\title{
The Impact of Quarantine on Sleep Quality and Psychological Distress During the COVID-19 Pandemic
}

\author{
Maha M AIRasheed (D) \\ Afnan M Alkadir \\ Khulood I Bin Shuqiran' \\ Sinaa Al-Aqeel (D) \\ Haitham A Jahrami iD ${ }^{2,3}$ \\ Ahmed S BaHammam (iD ${ }^{4,5}$ \\ 'Clinical Pharmacy Department, College \\ of Pharmacy, King Saud University, \\ Riyadh, Saudi Arabia; ${ }^{2}$ Ministry of Health, \\ Manama, Kingdom of Bahrain; ${ }^{3}$ College of \\ Medicine and Medical Sciences, Arabian \\ Gulf University, Manama, Bahrain; \\ ${ }^{4}$ University Sleep Disorders Centre, \\ Department of Medicine, College of \\ Medicine, King Saud University, Riyadh, \\ Saudi Arabia; ${ }^{5}$ The Strategic Technologies \\ Program of the National Plan for Sciences \\ and Technology and Innovation in the \\ Kingdom of Saudi Arabia, Riyadh, Saudi \\ Arabia
}

Purpose: We investigated the impact of isolation on sleep quality and psychological distress during the COVID-19 pandemic in Saudi Arabia.

Methods: An online survey was conducted on 353 (88 isolated and 265 not isolated) individuals from May to June 2020. Subjective sleep quality was determined using the Pittsburgh sleep quality index (PSQI), and psychological distress measured using the Kessler psychological distress scale (K10).

Results: The mean age of the isolated group was 28.6 years versus 27.5 years for the nonisolated group, with male participants accounting for $37 \%$ in both groups. The mean PSQI score was $8.5 \pm 3.6$ and $8.4 \pm 3.5$ for the isolated and non-isolated groups, respectively $(\mathrm{P}=$ 0.92). The mean K-10 score was $27.6 \pm 9.4$ and $25.3 \pm 9.5$ for the isolated and non-isolated groups, respectively $(\mathrm{P}=0.04)$. Poor sleep (PSQI $\geq 6)$ was reported in $235(66.6 \%)$ and psychological distress $(\mathrm{K}-10 \geq 20)$ in $244(69.1 \%)$ participants. Isolation was not associated with poor sleep (OR: 0.73 (95\% CI: $0.41-1.3), \mathrm{P}=0.29)$, but was statistically significant with psychological distress (OR: 2.12 (95\% CI: 1.10-4.08), $\mathrm{P}=0.03$ ).

Conclusion: Poor sleep and psychological distress symptoms were highly prevalent in our study population. Isolation may influence psychological distress but not sleep quality during the COVID-19 pandemic.

Keywords: SARS-CoV-2, COVID-19, pandemic, quarantine, sleep quality, psychological distress, self-isolation

\section{Introduction}

Severe acute respiratory syndrome (SARS) coronavirus 2 (SARS-CoV-2) is an acute form of a respiratory syndrome caused by a novel RNA beta coronavirus from the same family as SARS and the Middle East respiratory syndrome (MERS) coronaviruses. The first case of the disease, now commonly known as COVID-19, was detected in December 2019 in Wuhan City, China, and it was declared a global pandemic on 11th March 2020 by the World Health Organization. ${ }^{1}$ The pandemic spread rapidly, reaching alarming heights worldwide within a matter of months, with devastating consequences. The number of affected has risen to more than 174 million and total deaths to more than 3.7 million as of $11^{\text {th }}$ June $2021 .^{2}$

The continuous spread of the epidemic combined with the measures imposed by the governments such as social distancing, wearing masks, as well as the fear of contracting the infection is associated with poor sleep quality and psychosocial problems. A recent systematic review and a meta-analysis of sleep problems during
Correspondence: Maha M AlRasheed Clinical Pharmacy Department, College of Pharmacy, King Saud University, P.O. Box 2457, Riyadh, I I45I, Saudi Arabia

Tel +966I I 4678707

Fax +966- II-4677480

Email mahalrasheed@ksu.edu.sa 
the COVID-19 pandemic identified that patients infected with COVID-19 appear to be the most affected individuals with sleep problem at a prevalence rate of $74.8 \%(95 \%$ confidence interval (CI): $28.7-95.6 \%$ ) compared to $36.0 \%$ $(21.1-54.2 \%)$ and $32.3 \%(25.3-40.2 \%)$ in the general population and healthcare worker, respectively. ${ }^{3}$ Other reviews on the impact of COVID-19 on mental health found an increase in the prevalence of generalized anxiety disorders, worsening of psychiatric symptoms, increased depression/depressive symptoms, psychological distress, post-traumatic stress symptoms. ${ }^{4-8}$ These studies were conducted mainly in the general population or healthcare workers, and few examined the impact of the pandemic on patients infected with COVID-19.

Understandably, governments worldwide implemented mitigation measures such as lockdowns, quarantine, and travel restrictions not only between countries but also within individual countries or even communities to slow the spread of the virus. ${ }^{9,10}$ These containment measures can reduce the level of physical activity, and the exposure to daylight subsequently impact the pace of the flow of time, ${ }^{11}$ disrupt night-time sleep, ${ }^{12,13}$ and increase the risk of mental health problems. A review of studies that assessed mental health indexes such as overall psychological distress, depressive and post-traumatic stress disorder (PTSD) symptoms during and after quarantine periods in different pandemic outbreaks (eg, COVID-19, Severe Acute Respiratory Syndrome, Middle East Respiratory Syndrome) found that $20 \% \quad(95 \%$ CI: 14.47-27.21\%) of individuals exposed to restrictive measures reported clinically significant levels of psychological distress during and after pandemic infections that required quarantine containment interventions. The review included 21 studies; only 12 studies were during COVID-19, mainly from China $(n=5)$, Italy $(n=4)$, Spain $(n=2)$, and Lebanon $(n=1) .{ }^{14}$ Research suggests that lockdowns result in a worsening of sleep quality, ${ }^{15-21}$ a decrease in the amount and regularity of sleep, ${ }^{18,22}$ increased sleep duration and latency, ${ }^{15}$ and insomnia symptoms. ${ }^{17}$ These studies examined the impact of lockdown on the general population sleep quality and mental health; however, not much evidence on the impact of self-isolation or self-quarantine at home or in institutional centers imposed by many governments on those infected with COVID-19, exposed to infected people, or travelers who arrived from outside the country. Therefore, the present study aimed to examine the impact of selfisolation and self-quarantine on sleep quality and psychological distress during the COVID-19 pandemic in Saudi Arabia. Understanding the impact of the COVID-19 pandemic on sleep and mental health could help inform the public on health recommendations to maintain community wellbeing, particularly for possible future waves of COVID-19.

Following the announcement of the first case in Saudi Arabia on 2nd March 2020, a nationwide curfew was put into place on 24th March with movement restriction between $7 \mathrm{pm}$ and $6 \mathrm{am}$. The country continued to impose full and partial curfews to limit the virus from spreading until the curfew was ended on $20^{\text {th }}$ June 2020 (Supplemental Table 1: COVID-19 in Saudi Arabia during the study period). Schools, universities, and shops were closed during the lockdown, except for those selling essential goods such as food stores, supermarkets, and pharmacies. The Saudi Center for Disease Prevention and Control (SCDC) definition of quarantine is "to restrict the activities or separate people suspected of being exposed to contagious diseases and have no symptoms or a positive result, to reduce the spread of infection in a designated facility or at home with applying specific requirements" and isolation is "to separate the infected person (has a positive result) or have symptoms (suspected of having an infectious disease) to reduce the spread of infection either in the hospital or at home, according to the patient's health condition".

According to the SCDC guidelines, all travelers who arrived in Saudi Arabia must undergo self-quarantine. The period of isolation was 14 days, then reduced to 7 days without the need for a laboratory test if they have no symptom, or three days if there is a negative PCR test taken. Also, COVID-19 confirmed cases who did not show any symptoms must spend at least ten days in home isolation, and those who had mild symptoms spent at least three days in home isolation after improvement of symptoms.

\section{Methods}

This research was a cross-sectional questionnaire-based study. The sampling period was between 8th May and 29th June 2020. At the time of the survey distribution, Saudi Arabia was amid partial lockdown, social distancing, and travel restrictions. Social distancing measures included keeping a minimum of 1.5 meters between two individuals, a ban on any public gatherings, a limit of no more than five people at personal gatherings such as 
weddings and funerals, and no permission to meet with more than one other person outside of one's household. Lockdown restrictions also included the closure of restaurants and many retail stores and restricted access to outdoor parks.

\section{Participants}

Eligible participants included all Saudi Arabia residents aged 18 years and above, capable of reading and understanding the questionnaire, which was available in Arabic and English for participants to select their language of preference. We stratified the participant into two groups. Group 1 (isolated group) included those who went into isolation in their homes or special governmental facilities because they were diagnosed with or suspected of harboring COVID-19, and Group 2 (non-isolated group) included age- and sex-matched group of individuals from the public affected by COVID-19 prevention strategies, but were not isolated from their family members or community. Using power and sample size calculations for observational studies, we calculated that a minimum of 70 candidates was needed per group to provide the minimum of $80 \%$ power to reveal a significant difference of one point in the Pittsburgh sleep quality index (PSQI) using independent samples $t$-test with an alpha of 0.05 and beta of 0.2 . To account for covariates and increase power by $90 \%$, we utilized the ratio of $1: 3$ to compare cases in isolation to those not in isolation.

\section{Survey Instruments}

The online questionnaire was constructed using a Google Form with a dedicated account created and administered by the principal investigator. The survey questionnaire elicited information on sociodemographic characteristics, social interaction, and COVID-19-related data (Supplementary Table 2: Survey questionnaire). We used the Arabic version of PSQI obtained from MAPI Research Trust with demonstrated translation and validation. ${ }^{23}$ Over the preceding 30 days, subjective sleep quality was measured using the Pittsburgh sleep quality index (PSQI). ${ }^{24}$ The PSQI comprised seven components: subjective sleep quality, sleep duration, sleep onset latency, sleep efficiency, sleep disturbances, use of sleep medications, and daytime dysfunction. Each component was scored on a scale from 0 to 3 , yielding a global score ranging from 0 to 21. A higher PSQI total score indicates a lower sleep quality, whereby a global PSQI score of $\geq 6$ suggests poor sleep quality. ${ }^{24}$ Using a cut-off score of $\geq 6$, the PSQI has a sensitivity of $89.6 \%$ and specificity of $86.5 \%$ for detecting cases of sleep problems. ${ }^{25}$

Psychological distress was measured using the Kessler psychological distress scale (K10), a 10-item questionnaire intended to yield a global measure of distress based on questions about psychological distress that a person has experienced in the most recent four-week periods. ${ }^{26}$ The total score of $<20$ was considered not to represent no stress, while that $\geq 20$ represent psychological distress. Specifically, a score of 20-24 represents mild stress, 2529 represents moderate stress, and 30-50 represents severe stress. We used the Arabic version of K10 obtained from the Health Translation online library, ${ }^{27}$ demonstrating translation and psychometric properties. ${ }^{26}$ At the cut-off score of $>19$, the K-10 has a sensitivity of $71 \%$ and a specificity of $90 \%$ in detecting psychological distress. ${ }^{28}$

\section{Procedure}

The invitation to participate in the study was delivered through common social media platforms (Twitter and WhatsApp). Also, invitations were sent to special governmental facilities to be shared with isolated patients admitted due to COVID-19 infection or suspicion. Participants answered the questionnaire by scanning the Quick Response code (Q.R. code) of the questionnaire address or clicking the relevant link. The study was conducted following the declaration of Helsinki's ethical principles. The IRB Committee at King Saud University Medical City (E-20-4869) approved the study. Electronic informed consent was obtained from the respondents before starting to answer the questionnaire. In this research, the participation was entirely voluntary; no monetary or non-monetary rewards were provided, and participants were free to leave at any time.

\section{Statistical Analysis}

The Shapiro-Wilk test was used to test the normality of the study variables before the analyses. Descriptive statistics included count frequencies and percentages for categorical variables as well as means and standard deviations (S.D.) for continuous variables. The outcome variable sleep quality measured by PSQI was categorized dichotomously as good sleep quality (PSQI $\leq 5$ ) or poor sleep quality (PSQI $\geq 6$ ) group. The outcome variable psychological distress measured by $\mathrm{K} 10$ was categorized dichotomously as $<20$ being considered to represent no stress, while $\geq 20$ represents psychological distress. The three stress levels (mild, moderate, and severe) were put into 
one category and titled "presence of psychological stresses" . K-10 score of 20-24 represented mild stress, 25-29 represented moderate stress, and 30-50 represented severe stress.

Pearson product-moment correlation coefficient ( $\mathrm{r}=$ Pearson's correlation) was used to examine the association between PSQI and K-10. We then compared the two groups regarding the two primary study outcomes: (1) sleep quality and (2) psychological distress. The difference between the two groups was estimated for basic demographic and other characteristics. Independent samples $t$-test was used to compare continuous variables, and Pearson $\mathrm{Chi}^{2}$ statistic was used to compare categorical variables.

We performed multiple logistic regression modeling to determine the association of the two primary study outcomes: (1) sleep quality (measured by PSQI) and (2) psychological distress (measured by K10), with different covariate. The two primary outcomes became the dependent variable, while all sociodemographic and other variables were entered as the independent variables. Based on the literature review, we included isolation status, age, gender, provinces of Saudi Arabia, social interaction, social media use, current covid-19 infection, symptomatic covid-19 infection, existing medical comorbidity, shiftwork, poor sleep, psychological distress and psychotropic or sleep medication use as independent variables in univariate analysis. ${ }^{29-34}$ "Isolation" as well as variables with a P-value of less than 0.1 in the univariable analysis were included in the multivariable analysis. We reported the odds ratio and associated 95\% Confidence Intervals (95\% CI). For all statistical analyses, two-tailed tests were uses, and $\mathrm{p}$ values $<0.05$ were considered statistically significant. All statistical procedures were performed using Stata 16 (StataCorp. Stata, M.P. 16.1. StataCorp.; College Station, TX, USA: 2020) ${ }^{35}$ and R for statistical computing version $4.0 .3^{36}$

\section{Results}

\section{Sociodemographic and Clinical Characteristic Data}

The study included a total of 353 participants; 88 were in isolation because they had current or suspected COVID-19 infection or because they had just arrived from abroad, with 265 non-isolated individuals serving as controls. The age of the isolated group was $28.6 \pm 9.8$ (mean \pm standard deviation) years versus $27.5 \pm 8.5$ years for the non-isolated group, with males accounting for $37 \%$ in both groups, suggesting that both groups are age- and sex-matched. The majority of the participants were Saudi nationals (approximately 92\%), involving approximately 64\% single individuals and approximately 76\% non-health sector workers. The distribution for these variables showed no statistically significant difference between the isolation and non-isolation groups. There was, however, a significant difference between the two groups in social interaction, with $42(50.6 \%)$ participants in the isolated group who loves and waits for social events and 108 $(41.1 \%)(\mathrm{P}=0.01)$ in the non-isolated group being neutral in their social interaction response.

The clinical characteristics showed that $24(27.3 \%)$ of the isolated group versus two individuals $(0.8 \%)$ in the nonisolated group had current COVID-19 infection ( $\mathrm{P}=0.001)$. A statistically significant proportion of the patients with positive COVID-19 ( $\approx 80 \%)$ had asymptomatic COVID-19 infection in the isolation group versus none in the nonisolated group $(\mathrm{P}=0.001)$. Individuals in the isolation group had a slightly higher prevalence of chronic medical conditions compared to those in the non-isolated group (14.8\% and $12.5 \%$, respectively). The difference was not statistically significant. Finally, those individuals in the non-isolation group compared to the patients in the isolated group had a higher intake of psychotropics or sleep modification (17.4\% and $11.4 \%$, respectively, $\mathrm{P}=0.18$ ). The complete details of sociodemographic and patient characteristic data are available in Table 1.

\section{PSQI and KIO Scores}

Figure 1 depicts the box plot of the PSQI and K-10 scores in both the isolation and non-isolation groups. The mean PSQI score was $8.5 \pm 3.6$ (mean \pm standard deviation) for the isolated and $8.4 \pm 3.5$ for the non-isolated group $(\mathrm{P}=0.92)$. The prevalence of poor sleep quality (PSQI $\geq 6$ ) was slightly higher in the non-isolation group $(80 \%)$ compared to the isolation group $(73.9 \%)$. The difference did not reach statistical significance $(\mathrm{P}=0.22)$. A detailed analysis of the sleep quality sub-scales revealed that both groups scored similarly on the various PSQI components. Detailed results of the PSQI and its components are available in Table 2 .

The mean K-10 scores were 27.6 \pm 9.4 and $25.3 \pm 9.5$ for isolated and non-isolated groups, respectively $(\mathrm{P}=0.04)$, suggesting that patients in the non-isolated group had slightly lower K-10 scores. The prevalence of psychological distress categories was higher in the isolation group $(\approx 77 \%$ ) compared with the non-isolation group $(\approx 66 \%)$, 
Table I Socio-Demographics and Clinical Characteristics of the Study Participants Comparing Isolation versus No Isolation

\begin{tabular}{|c|c|c|c|c|}
\hline Variable & $\begin{array}{l}\text { Total Sample } \\
N=353\end{array}$ & $\begin{array}{l}\text { Isolation } \\
\mathbf{N}=\mathbf{8 8}\end{array}$ & $\begin{array}{l}\text { No Isolation } \\
\mathbf{N}=265\end{array}$ & P-value \\
\hline Age, years & $27.8 \pm 8.8$ & $28.6 \pm 9.8$ & $27.5 \pm 8.5$ & 0.32 \\
\hline Male & $132(37.4 \%)$ & $33(37.5 \%)$ & 99 (37.4\%) & 0.99 \\
\hline $\begin{array}{l}\text { Nationality } \\
\text { Saudi } \\
\text { Non-Saudi }\end{array}$ & $\begin{array}{l}324(91.8 \%) \\
29(8.2 \%)\end{array}$ & $\begin{array}{l}85(96.6 \%) \\
3(3.4 \%)\end{array}$ & $\begin{array}{l}239(90.2 \%) \\
26(9.8 \%)\end{array}$ & 0.06 \\
\hline $\begin{array}{l}\text { Marital status } \\
\text { Single } \\
\text { Married } \\
\text { Divorced/widowed/separated }\end{array}$ & $\begin{array}{l}226(64 \%) \\
118(33.4 \%) \\
9(2.6 \%)\end{array}$ & $\begin{array}{l}54(61.4 \%) \\
31(35.2 \%) \\
3(3.4 \%)\end{array}$ & $\begin{array}{l}172(64.9 \%) \\
87(32.8 \%) \\
6(2.3 \%)\end{array}$ & 0.74 \\
\hline Do you work in a health sector? (Yes) & $88(24.9 \%)$ & 21 (23.9\%) & $67(25.3 \%)$ & 0.79 \\
\hline Do you have children? (Yes) & $104(29.5 \%)$ & $33(37.5 \%)$ & $7 \mathrm{l}(26.8 \%)$ & 0.06 \\
\hline Do you work shifts? (Yes) & $89(25.2 \%)$ & 21 (23.9\%) & $68(25.7 \%)$ & 0.74 \\
\hline $\begin{array}{l}\text { How many members of your family live with you at home } \\
\text { (including you)? } \\
\text { One to two persons } \\
\text { Three to five persons } \\
\text { More than five persons }\end{array}$ & $\begin{array}{l}62(17.6 \%) \\
100(28.3 \%) \\
191(54.1 \%)\end{array}$ & $\begin{array}{l}23(26.1 \%) \\
23(26.1 \%) \\
42(47.7 \%)\end{array}$ & $\begin{array}{l}39(14.7 \%) \\
77(29.1 \%) \\
149(56.2 \%)\end{array}$ & 0.05 \\
\hline $\begin{array}{l}\text { Job-status } \\
\text { I do not work } \\
\text { Employee } \\
\text { Self-employed } \\
\text { Student }\end{array}$ & $\begin{array}{l}48(13.6 \%) \\
146(41.4 \%) \\
14(4 \%) \\
145(41.1 \%)\end{array}$ & $\begin{array}{l}7(8 \%) \\
38(43.2 \%) \\
\text { Nil }(0 \%) \\
43(48.9 \%)\end{array}$ & $\begin{array}{l}41(15.5 \%) \\
108(40.8 \%) \\
14(5.3 \%) \\
102(38.5 \%)\end{array}$ & 0.03 \\
\hline $\begin{array}{l}\text { Educational level } \\
\text { Middle school or lower, High school or Diploma } \\
\text { Bachelor's degree or higher }\end{array}$ & $\begin{array}{l}67(19 \%) \\
286(81 \%)\end{array}$ & $\begin{array}{l}14(15.9 \%) \\
74(84.1 \%)\end{array}$ & $\begin{array}{l}53(2 \%) \\
212(8 \%)\end{array}$ & 0.40 \\
\hline $\begin{array}{l}\text { Monthly income }(\mathbf{n = 3 1 6}) \\
\text { I do not want to answer } \\
<1000 \text { SR } \\
1000-2999 \text { SR } \\
3000-5999 \text { SR } \\
6000-9999 \text { SR } \\
10,000-30,000 \text { SR } \\
>30,000\end{array}$ & $\begin{array}{l}105(33.2 \%) \\
56(17.7 \%) \\
37(11.7 \%) \\
16(5.1 \%) \\
34(10.8 \%) \\
59(18.7 \%) \\
9(2.9 \%)\end{array}$ & $\begin{array}{l}24(33.3 \%) \\
11(15.3 \%) \\
8(11.1 \%) \\
2(2.8 \%) \\
14(19.4 \%) \\
11(15.3 \%) \\
2(2.8 \%)\end{array}$ & $\begin{array}{l}81(33.2 \%) \\
45(18.4 \%) \\
29(11.9 \%) \\
14(5.7 \%) \\
20(8.2 \%) \\
48(19.8 \%) \\
7(2.9 \%)\end{array}$ & 0.20 \\
\hline $\begin{array}{l}\text { The region where you live } \\
\text { Riyadh } \\
\text { Other }\end{array}$ & $\begin{array}{l}215(68 \%) \\
138(39.1 \%)\end{array}$ & $\begin{array}{l}47(65.4 \%) \\
41 \text { (46.6\%) }\end{array}$ & $\begin{array}{l}168 \text { (68.9\%) } \\
97(36.6 \%)\end{array}$ & 0.09 \\
\hline $\begin{array}{l}\text { Social interaction }(\mathbf{n}=\mathbf{3 4 6}) \\
\text { Loves and waits for social events } \\
\text { Gets bored of social events and does not go there } \\
\text { Hates social events and does not go there } \\
\text { Neutral }\end{array}$ & $\begin{array}{l}126(36.4 \%) \\
53(15.3 \%) \\
31(9 \%) \\
136(39.3 \%)\end{array}$ & $\begin{array}{l}42(50.6 \%) \\
10(12.1 \%) \\
3(3.6 \%) \\
28(33.7 \%)\end{array}$ & $\begin{array}{l}84(31.9 \%) \\
43(16.4 \%) \\
28(10.7 \%) \\
108(41.1 \%)\end{array}$ & 0.01 \\
\hline
\end{tabular}

(Continued) 
Table I (Continued).

\begin{tabular}{|c|c|c|c|c|}
\hline Variable & $\begin{array}{l}\text { Total Sample } \\
\mathbf{N}=353\end{array}$ & $\begin{array}{l}\text { Isolation } \\
\mathbf{N}=\mathbf{8 8}\end{array}$ & $\begin{array}{l}\text { No Isolation } \\
\mathbf{N}=\mathbf{2 6 5}\end{array}$ & P-value \\
\hline $\begin{array}{l}\text { I have good information about coronavirus and its ways of } \\
\text { spreading } \\
\text { Highly agree } \\
\text { Agree } \\
\text { Neutral } \\
\text { 'Disagree } \\
\text { Highly disagree }\end{array}$ & $\begin{array}{l}302(85.6 \%) \\
12(3.4 \%) \\
30(8.5 \%) \\
6(1.7 \%) \\
3(0.9 \%)\end{array}$ & $\begin{array}{l}69(78.4 \%) \\
6(6.8 \%) \\
\text { II }(12.5 \%) \\
2(2.3 \%) \\
\text { Nil }(0 \%)\end{array}$ & $\begin{array}{l}233(87.9 \%) \\
6(2.3 \%) \\
19(7.2 \%) \\
4(1.5 \%) \\
3(1.1 \%)\end{array}$ & 0.08 \\
\hline $\begin{array}{l}\text { I feel very afraid because there is no approved drug to treat } \\
\text { coronavirus COVIDI9 } \\
\text { Highly agree } \\
\text { Agree } \\
\text { Neutral } \\
\text { Disagree } \\
\text { Highly disagree }\end{array}$ & $\begin{array}{l}66 .(18.7 \%) \\
123(34.8 \%) \\
84(23.8 \%) \\
62(17.6 \%) \\
18(5.1 \%)\end{array}$ & $\begin{array}{l}14(15.9 \%) \\
32(36.4 \%) \\
20(22.7 \%) \\
15(17.1 \%) \\
7(8 \%)\end{array}$ & $\begin{array}{l}52(19.6 \%) \\
91(34.3 \%) \\
64(24.2 \%) \\
47(17.7 \%) \\
11(4.2 \%)\end{array}$ & 0.64 \\
\hline $\begin{array}{l}\text { Coronavirus news on social media increases my anxiety and fear } \\
\text { Highly agree } \\
\text { Agree } \\
\text { Neutral } \\
\text { Disagree } \\
\text { Highly disagree }\end{array}$ & $\begin{array}{l}82(23.2 \%) \\
120(34 \%) \\
59(16.7 \%) \\
77(21.8 \%) \\
15(4.3 \%)\end{array}$ & $\begin{array}{l}20(22.7 \%) \\
35(39.8 \%) \\
13(14.8 \%) \\
17(19.3 \%) \\
3(3.4 \%)\end{array}$ & $\begin{array}{l}62(23.4 \%) \\
85(32.1 \%) \\
46(17.4 \%) \\
60(22.6 \%) \\
12(4.5 \%)\end{array}$ & 0.74 \\
\hline $\begin{array}{l}\text { Curfew hours during the past month } \\
\text { Partial curfew } 6 \text { am }-3 \text { pm } \\
\text { Partial curfew } 6 \text { am }-8 \text { pm. Penalties for not wearing a face mask } \\
\text { No curfew. Penalties for not wearing a face mask, refuse to be checked for } \\
\text { temperature }\end{array}$ & $\begin{array}{l}\text { I75 (49.6\%) } \\
\text { I75 (49.6\%) } \\
3(0.9 \%)\end{array}$ & $\begin{array}{l}16(18.2 \%) \\
70(79.6 \%) \\
2(2.3 \%)\end{array}$ & $\begin{array}{l}159(60 \%) \\
105(39.6 \%) \\
I(0.4 \%)\end{array}$ & 0.001 \\
\hline $\begin{array}{l}\text { Are your sleep habits affected by special occasions as Ramadan or vacations? } \\
\text { (Yes) }\end{array}$ & $330(93.5 \%)$ & $82(93.2 \%)$ & $248(93.6 \%)$ & 0.89 \\
\hline Do you have Coronavirus COVID-I9? (Yes) & $26(7.4 \%)$ & $24(27.3 \%)$ & $2(0.8 \%)$ & 0.001 \\
\hline Symptomatic COVID-I9? (Yes) & $21(6 \%)$ & $21(23.9 \%)$ & Nil & 0.001 \\
\hline Do you suffer from a chronic disease? (Yes) & $46(13 \%)$ & $13(14.8 \%)$ & $33(12.5 \%)$ & 0.23 \\
\hline Do you take any psychotropics or sleep medicine? (Yes) & $56(15.9 \%)$ & $10(11.4 \%)$ & $46(17.4 \%)$ & 0.18 \\
\hline
\end{tabular}

Notes: Continuous data were presented as mean \pm standard deviation and categorical data as numbers and percentages. Independent samples $t$-test was used for continuous data, and Pearson $\mathrm{Chi}^{2}$ test was used for categorical data. Statistical significance was set at $\mathrm{P}<0.05$.

with the difference trending toward statistical significance showing $\mathrm{P}=0.06$. Patients with psychological distress in both groups had an equally distributed distress severity according to $\mathrm{K}-10(\mathrm{P}=0.12)$, with most of the patients being in the severe stress category.

There was a significant positive correlation between the PSQI and the K-10 scores ( $r$ coefficient: $0.35 ; \mathrm{P}=$ 0.001). The association between PSQI and K-10 was stronger in the non-isolation group compared to the isolation group with $r$ coefficient: $0.38 ; \mathrm{P}=0.001$ and $r$ coefficient: $0.30 ; \mathrm{P}=0.005$, respectively (Table 2 ).

\section{Factors Associated with Poor Sleep Quality and Stress}

Isolation was not associated with poor sleep (OR: 0.73 (95\% CI: 0.41-1.3), $\mathrm{P}=0.29$ ), but was statistically significant with psychological distress (OR: 2.12 (95\% CI: 1.104.08), $\mathrm{P}=0.03$ ) (Table 3). 


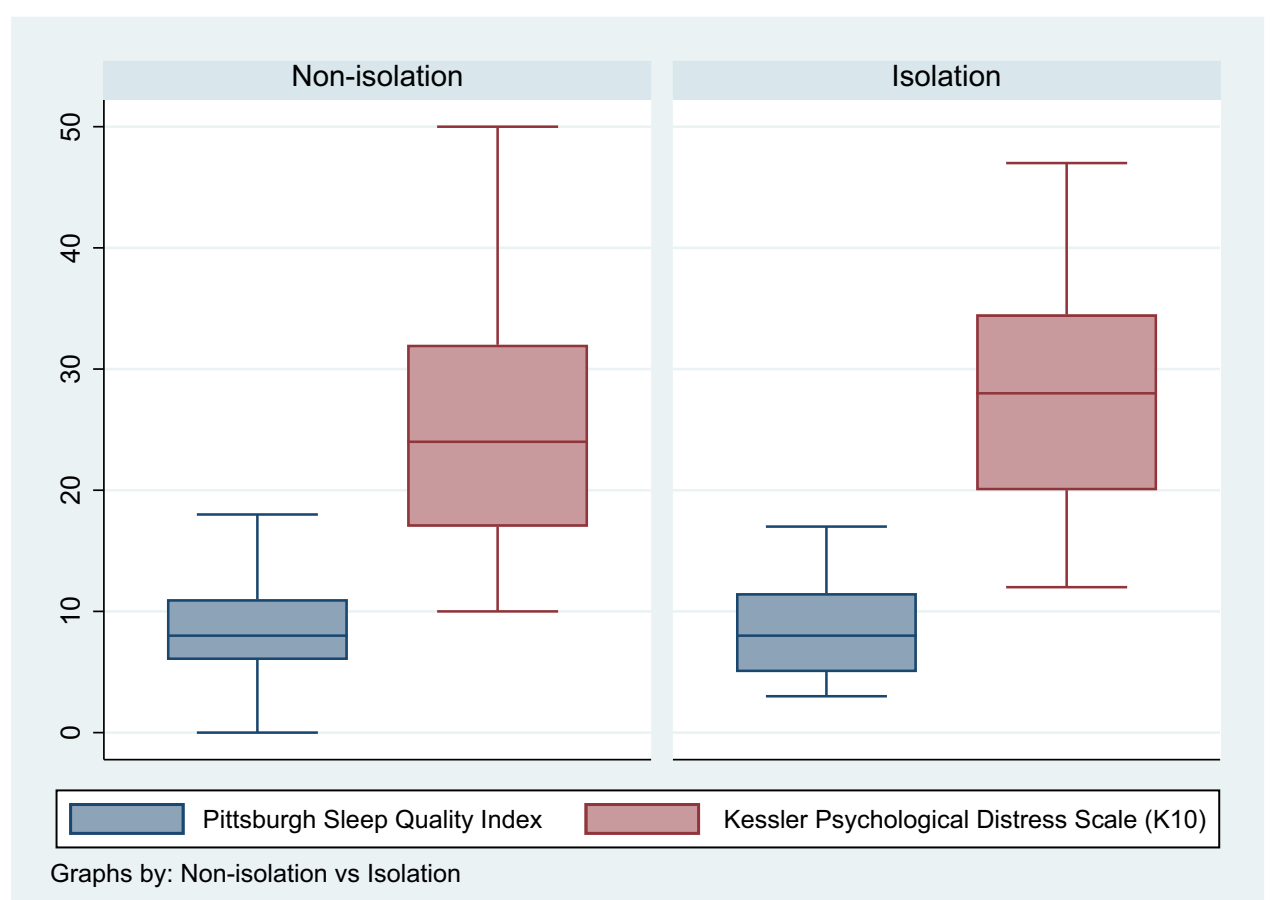

Figure I Box plot of the Pittsburgh sleep quality index (PSQI) score and Kessler psychological distress score (K-I0) in participants with isolation versus no isolation.

\section{Discussion}

In the present study, we addressed the impact of quarantining individuals on their sleep habits and psychological wellbeing in relation to the COVID-19 pandemic management in Saudi Arabia. Our results revealed a high PSQI score for the study population as a whole. However, there was no definable relationship between quarantine and changes in sleep quality, suggesting that the quarantine has no notable impact on this property in our study population. There is currently a lack of data on this aspect of the pandemic in the literature, necessitating in-depth studies to clarify this point further. On the other hand, however, investigators have reported the COVID-19 outbreak itself or subsequently imposed lockdowns as primarily exerting a negative impact on sleep quality,,$^{3,15,19-22,37}$ or also as lacking such a link with changes in sleep quality in the general population at large. ${ }^{13,38}$ Interestingly, however, rather than being related to quarantine, our results demonstrated that poor sleep quality was associated with social interaction and the use of social media.

Furthermore, unlike sleep quality, a higher prevalence of psychological distress was related to isolation in the present study, with significant variation among the psychological health characteristics. These observations are in concordance with the positive relationships that have been demonstrated between quarantine and adverse psychological behaviors in some studies. ${ }^{39-41}$ Notably, the available literature has also primarily addressed the impact of the COVID-19 onset itself or lockdowns, rather than quarantine, on the psychological health status of their study cohorts. ${ }^{5,6,14,38}$ Interestingly also, in several studies, negative psychological responses, such as generalized anxiety disorder as well as depressive or PTSD symptoms, appeared to correlate well with poor sleeping habits, pointing to some interdependence of the two characteristics in relation to the pandemic outbreak. ${ }^{8,16,17}$ In the present study, despite the different effects of isolation on sleep quality and psychological health status, their scores seemed to correlate well, also possibly indicative of some positive relationship between the two variables in general. Besides, adverse effects, particularly in the psychological characteristics, have similarly been linked partly to negative trends in physical activity, alcohol drinking, and smoking habits with the onset of the COVID-19 pandemic. ${ }^{42}$ Moreover, rather than the observed adverse effects being directly triggered by confinement, some prevailing confounders may discern between the impact of such stresses more appropriately, as suggested by studies linking psychological distress to gender, social standing, age, or pre-existing psychiatric conditions, such as PSTD symptoms, and prior exposure to trauma, among others. ${ }^{42-49}$ The study similarly identified the female gender as a factor of moderate-tosevere psychological stress in support of the notion that 
Table 2 Descriptive Findings of the Pittsburgh Sleep Quality Index (PSQI) and the Kessler Psychological Distress Scale (KI0) Comparing Isolation versus No Isolation

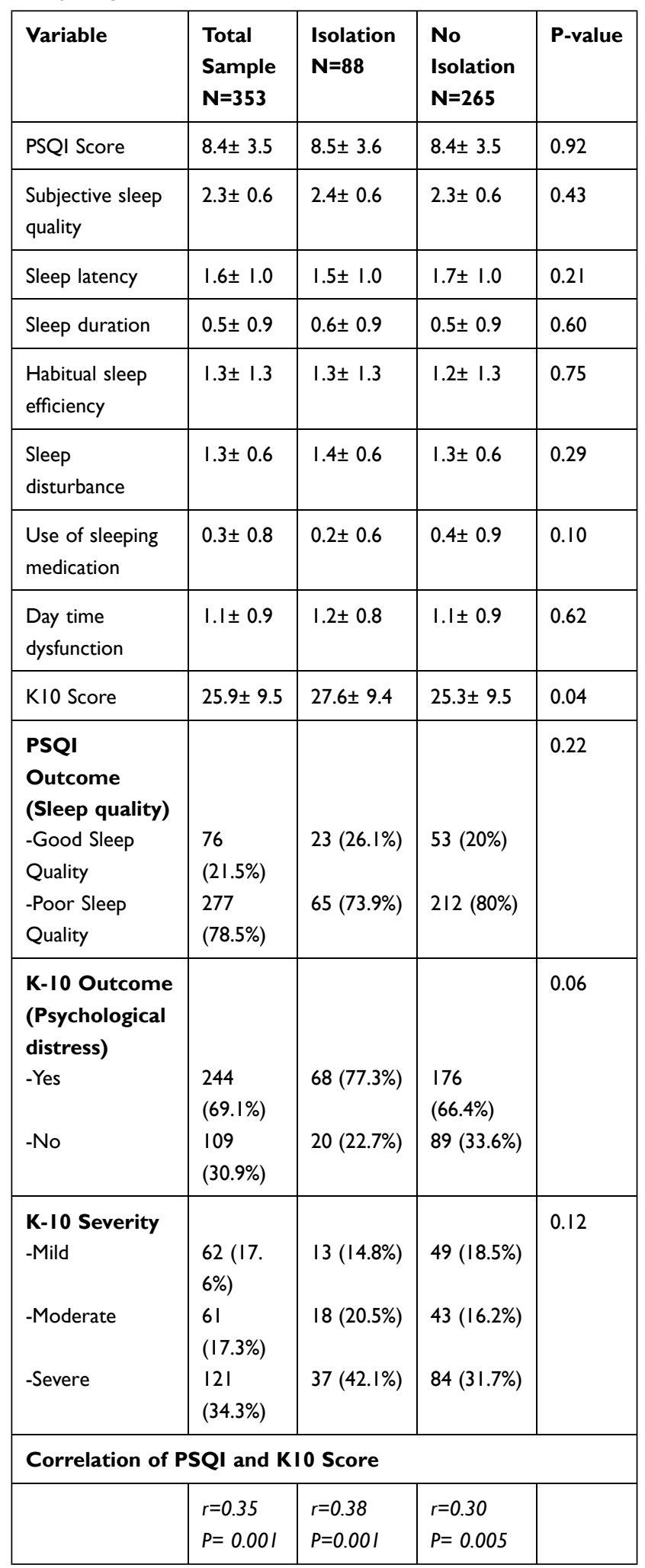

Notes: Continuous data were presented as mean \pm standard deviation and categorical data as numbers and percentages. Independent samples $t$-test was used for continuous data, and Pearson $\mathrm{Chi}^{2}$ statistics was used for categorical data. Statistical significance was set at $\mathrm{P}<0.05$. gender may influence such outcomes. Put together; these observations seem to suggest that the impact of lockdown or quarantine on the studied variables may be secondary to that of prevalent confounders.

The variations in the observations may also be indicative of other potentially contributory variables influencing these relationships. These factors may involve long-lasting post-traumatic stress, confusion, or anger triggered by stress emanating from socioeconomic factors, such as quarantine duration, infection fears, frustration, inadequacy in household necessities, financial loss, and stigma. ${ }^{39,50}$ In our study, isolated individuals also displayed higher signs of distress than their control counterparts. Not surprisingly, these behavioral trends are themselves generally born of the disease outbreak itself, since the arrival of the pandemic itself was stressful enough, with the measures to contain it globally being implemented at the expense of even higher socioeconomic cost and the wellbeing of, particularly, the frontline health workers. ${ }^{5,14,51-55}$ Other factors, including habitat or environmental conditions such as the disease outbreak location, for example, may also play a role in the manifestation of sleep or psychological disorders under these conditions. Indeed, consistent with other findings elsewhere, our study seems to suggest that the place of habitation may also matter. Altogether, these observations point to the negative influence of the advent of COVID-19 on sleep quality and mental health globally being exacerbated by both precluding pre-existing stresses and isolation. Hence, these risk factors need to be considered in establishing the impact of confinements on human movement on the psychological and physiological responses in such pandemic outbreaks.

Notably, as indicated by the divergence in the global observations, the response levels to the pandemic or related confinements may also vary among the different regions of the globe. This variation may presumably be partly due to how communities in the various areas of the world tend to absorb stress, whereby some may endure certain types of pressures and stress more lightly than others. Thus, for example, in less fortunate countries in which certain forms of environmental and physical stresses are almost a natural occurrence, lockdowns and quarantines are likely to impact their psychological responses to the pandemic stress less severely than in those countries where such forms of stress are virtually non-existent. In this regard, it should be noted that social isolation and loneliness can harm mental health ${ }^{49}$ and may constitute 
Table 3 Logistic Regression Analysis for the Association Between the Status of Poor Sleep Quality and Psychological Distress and Selected Characteristics of the Study Participants

\begin{tabular}{|c|c|c|c|c|}
\hline \multirow[t]{2}{*}{ Variables } & \multicolumn{2}{|c|}{ Univariable Analysis } & \multicolumn{2}{|c|}{ Multivariable Analysis } \\
\hline & OR $(95 \% \mathrm{Cl})$ & P-value & OR $(95 \% \mathrm{Cl})$ & P-value \\
\hline \multicolumn{5}{|l|}{ Sleep quality $(n=346)$} \\
\hline Isolation status (Yes) & $0.96(0.58-1.59)$ & 0.88 & $0.73(0.4 \mathrm{I}-\mathrm{I} .30)$ & 0.29 \\
\hline Age & I.0I (0.98-1.03) & 0.55 & - & - \\
\hline Female & $0.89(0.56-1.4 I)$ & 0.62 & - & - \\
\hline Living outside Riyadh & $0.85(0.54-1.34)$ & 0.50 & - & - \\
\hline Loves and waits for social events & $1.78(0.03-1.07)$ & 0.03 & $1.92(0.92-4.00)$ & 0.01 \\
\hline Coronavirus news on social media increases stress (Agree) & $2.88(1.58-5.24)$ & 0.001 & $2.12(1.11-4.05)$ & 0.02 \\
\hline Current COVID-19 infection (Yes) & $0.58(0.22-1.47)$ & 0.25 & - & - \\
\hline Existing medical comorbidity (Yes) & $1.08(0.55-2.05)$ & 0.83 & - & - \\
\hline Shiftwork (Yes) & $1.02(0.72-2.02)$ & 0.47 & - & - \\
\hline Psychotropic or sleep medication use (Yes) & $1.31(0.70-2.45)$ & 0.40 & - & - \\
\hline Symptomatic COVID-19 infection (Yes) & $0.43(0.17-1.05)$ & 0.06 & $0.77(0.29-2.04)$ & 0.60 \\
\hline Psychological distress & $3.7(2.30-5.96)$ & $<0.001$ & $3.27(1.93-5.54)$ & $<0.001$ \\
\hline \multicolumn{5}{|l|}{ Psychological distress $(n=353)$} \\
\hline Isolation status (Yes) & $1.71(0.98-3.01)$ & 0.06 & $2.12(1.10-4.08)$ & 0.03 \\
\hline Age & $0.98(0.96-1.01)$ & 0.35 & - & - \\
\hline Female & $2.10(|.3|-3.3 \mid)$ & 0.002 & $2.73(1.58-4.70)$ & $<0.001$ \\
\hline Living outside Riyadh & $1.84(1.14-3.00)$ & 0.01 & $1.79(1.01-3.16)$ & 0.046 \\
\hline Loves and waits for social events & $0.83(0.50-1.40)$ & 0.50 & - & - \\
\hline Coronavirus news on social media increases stress (Agree) & $3.45(1.88-6.32)$ & $<0.001$ & $2.45(1.24-4.84)$ & 0.01 \\
\hline Current COVID-19 infection (Yes) & $1.43(0.63-3.28)$ & 0.39 & - & - \\
\hline Existing medical comorbidity (Yes) & $2.56(1.37-4.82)$ & 0.003 & $2.61(1.23-5.53)$ & 0.01 \\
\hline Shiftwork (Yes) & $1.28(0.76-2.19)$ & 0.36 & - & - \\
\hline Psychotropic or sleep medication use (Yes) & $1.13(0.60-2.16)$ & 0.68 & - & - \\
\hline Symptomatic COVID-19 infection (Yes) & $0.30(0.12-0.76)$ & 0.01 & $0.29(0.10-0.83)$ & 0.02 \\
\hline Poor sleep & $3.7(2.30-5.96)$ & $<0.001$ & $3.63(2.12-6.24)$ & $<0.001$ \\
\hline
\end{tabular}

Notes: Variables with a P-value of less than 0.1 in the univariable analysis were included in the multivariable analysis, in addition to isolation. Multivariable model calibration was tested using the Hosmer-Lemeshow test and model discrimination using C-statistics and the area under the curve (AUC). (Hosmer-Lemeshow P for sleep quality model= 0.44 and for psychological distress model= 0.57 . AUC for sleep quality model= $0.7 \mathrm{I}$ and for psychological distress model= 0.80 ). "Sleep quality was measured using the Pittsburgh sleep quality index (PSQI), and psychological distress was measured using the Kessler psychological distress scale (KI0). (PSQI score $\geq 6$ indicated poor sleep $\mathrm{K}$ - 10 score $\geq 20$ represented psychological distress). Statistical significance $\mathrm{P}<0.05$ ".

a source of ill health, particularly in developing countries. This finding may be explained by the fact that those societies are more strongly family-oriented than the developed nations in general. Hence, the pressure of isolation would not necessarily bear similar psychological consequences on sleep as in developed countries, thereby contributing differently to the variations observed in the impact of quarantine and lockdown in the different regions of the world. Thus, predisposition to adverse effects on sleep quality and mental health comes not only through the mere presence of the disease but also through several other prevailing factors in addition to the confinements of the imposed lockdowns or quarantines.
The major strength of this study is the measurement of both sleep quality and psychological distress in one population allowed to examine the cross-examination of both outcomes simultaneously. There are some limitations to the interpretation of our result that may need to be considered. First, the recruitment procedure was a considerable source of bias since the study candidates were conscious of the format of study they were engaged in. Second, the derivation of data from such a crosssectional design renders causal inferences challenging. Third, the fact that the data was collected through an online survey, the only feasibly procedure as a result of social distancing, may explain the recruitment bias in our 
sample manifested by the high number of young adults, highly educated and female participants, thereby limiting the generalization of the results. Finally, the target outcomes and data related to predictive variables were collected through self-report participants, which was not necessarily supported by objective assessment.

\section{Conclusion}

In conclusion, quarantining individuals did not show any definable relationship with negative changes in sleep quality but displayed an association with adverse mental health conditions in our study population. However, these adverse effects appear to be related instead to comorbidities or covariates such as gender or habitat, indicating a role for these variables on the impact of the pandemicrelated confinement on affected individuals' physiological and psychological wellbeing.

\section{Abbreviations}

COVID-19, Severe acute respiratory syndrome Coronavirus subtype 2, 19; DASS scale, Depression Anxiety and Stress Scale; GAD, generalized anxiety disorder; K10, Kessler psychological distress scale; MERS, Middle East respiratory syndrome; MOH, (Saudi) Ministry of Health; PSQI, Pittsburgh sleep quality index; PTSD, Post-traumatic stress disorder; PTSS, Post-traumatic stress symptoms; SARS, Severe acute respiratory syndrome; SARS-CoV-2, Severe acute respiratory syndrome Coronavirus subtype 2; WHO, World Health Organization.

\section{Data Sharing Statement}

Data will be made available on request.

\section{Acknowledgment}

This research project was supported by a grant from the "Research Center of the Female Scientific and Medical Colleges", Deanship of Scientific Research, King Saud University.

\section{Disclosure}

The authors declare no conflicts of interest for this work.

\section{References}

1. Sohrabi C, Alsafi Z, O'Neill N, et al. World Health Organization declares global emergency: a review of the 2019 novel coronavirus (COVID-19). Int $J$ Surg. 2020;76:71-76. doi:10.1016/j. ijsu.2020.02.034
2. World Health Organization. WHO Coronavirus Disease (COVID-19) dashboard;. Geneva: 2020. Available from: https://covid19.who.int/. Accessed June 24, 2021.

3. Jahrami H, BaHammam AS, Bragazzi NL, Saif Z, Faris M, Vitiello MV. Sleep problems during the COVID-19 pandemic by population: a systematic review and meta-analysis. J Clin Sleep Med. 2021;17(2):299-313. doi:10.5664/jcsm.8930

4. da Silva ML, Rocha RSB, Buheji M, Jahrami H, Cunha KDC. A systematic review of the prevalence of anxiety symptoms during coronavirus epidemics. J Health Psychol. 2021;26(1):115-125. doi: $10.1177 / 1359105320951620$

5. Vindegaard N, Benros ME. COVID-19 pandemic and mental health consequences: systematic review of the current evidence. Brain Behav Immun. 2020;89:531-542. doi:10.1016/j.bbi.2020.05.048

6. Xiong J, Lipsitz O, Nasri F, et al. Impact of COVID-19 pandemic on mental health in the general population: a systematic review. $J$ Affect Disord. 2020;277:55-64. doi:10.1016/j.jad.2020.08.001

7. Santabárbara J, Lasheras I, Lipnicki DM, et al. Prevalence of anxiety in the COVID-19 pandemic: an updated meta-analysis of community-based studies. Prog Neuropsychopharmacol Biol Psychiatry. 2020;109:110207. doi:10.1016/j.pnpbp.2020.110207

8. Salari N, Hosseinian-Far A, Jalali R, et al. Prevalence of stress, anxiety, depression among the general population during the COVID-19 pandemic: a systematic review and meta-analysis. Global Health. 2020;16(1):57. doi:10.1186/s12992-020-00589-w

9. Barry M, Ghonem L, Alsharidi A, et al. Coronavirus disease-2019 pandemic in the Kingdom of Saudi Arabia: mitigation measures and hospital preparedness. J Nat Sci Med. 2020;3(3):155-158.

10. Manzar M, Pandi-Perumal S, Bahammam A. Lockdowns for community containment of COVID-19: present challenges in the absence of interim guidelines. J Nat Sci Med. 2020;3(4):318-321.

11. Zakay D. Psychological time as information: the case of boredom. Front Psychol. 2014;5:917. doi:10.3389/fpsyg.2014.00917

12. Altena E, Baglioni C, Espie CA, et al. Dealing with sleep problems during home confinement due to the COVID-19 outbreak: practical recommendations from a task force of the European CBT-I Academy. J Sleep Res. 2020;29(4):e13052. doi:10.1111/jsr.13052

13. Blume C, Schmidt MH, Cajochen C. Effects of the COVID-19 lockdown on human sleep and rest-activity rhythms. Curr Biol. 2020;30 (14):R795-r797. doi:10.1016/j.cub.2020.06.021

14. Cavicchioli M, Ferrucci R, Guidetti M, Canevini MP, Pravettoni G, Galli F. What will be the impact of the Covid-19 quarantine on psychological distress? Considerations based on a systematic review of pandemic outbreaks. Healthcare. 2021;9(1). doi:10.3390/ healthcare 9010101

15. Cellini N, Conte F, De Rosa O, et al. Changes in sleep timing and subjective sleep quality during the COVID-19 lockdown in Italy and Belgium: age, gender and working status as modulating factors. Sleep Med. 2021;77:112-119. doi:10.1016/j.sleep.2020.11.027

16. Franceschini C, Musetti A, Zenesini C, et al. Poor sleep quality and its consequences on mental health during the COVID-19 lockdown in italy. Front Psychol. 2020;11:574475. doi:10.3389/ fpsyg.2020.574475

17. Salfi F, Lauriola M, Amicucci G, et al. Gender-related time course of sleep disturbances and psychological symptoms during the COVID-19 lockdown: a longitudinal study on the Italian population. Neurobiol Stress. 2020;13:100259. doi:10.1016/j. ynstr.2020.100259

18. Cheikh Ismail L, Osaili TM, Mohamad MN, et al. Eating habits and lifestyle during COVID-19 lockdown in the United Arab Emirates: a Cross-Sectional Study. Nutrients. 2020;12(11):3314. doi:10.3390/ nu12113314

19. Trabelsi K, Ammar A, Masmoudi L, et al. Globally altered sleep patterns and physical activity levels by confinement in 5056 individuals: ECLB COVID-19 international online survey. Biol Sport. 2020;495-506. 
20. Casagrande M, Forte G, Tambelli R, Favieri F. The coronavirus pandemic: a possible model of the direct and indirect impact of the pandemic on sleep quality in Italians. Nat Sci Sleep. 2021;13:191-199. doi:10.2147/NSS.S285854

21. Martínez-Lezaun I, Santamaría-Vázquez M, Del Líbano M. Influence of confinement by COVID-19 on the quality of sleep and the interests of university students. Nat Sci Sleep. 2020;12:1075-1081. doi:10.2147/NSS.S280892

22. Costi S, Paltrinieri S, Bressi B, Fugazzaro S, Giorgi Rossi P, Mazzini E. Poor sleep during the first peak of the SARS-CoV-2 pandemic: a Cross-Sectional Study. Int J Environ Res Public Health. 2021;18(1):306. doi:10.3390/ijerph18010306

23. Suleiman KH, Yates BC, Berger AM, Pozehl B, Meza J. Translating the pittsburgh sleep quality index into arabic. West $J$ Nurs Res. 2010;32(2):250-268. doi:10.1177/0193945909348230

24. Buysse DJ, Reynolds CF 3rd, Monk TH, Berman SR, Kupfer DJ. The pittsburgh sleep quality index: a new instrument for psychiatric practice and research. Psychiatry Res. 1989;28(2):193-213. doi:10.1016/0165-1781(89)90047-4

25. Buysse DJ, Hall ML, Strollo PJ, et al. Relationships between the Pittsburgh Sleep Quality Index (PSQI), Epworth Sleepiness Scale (ESS), and clinical/polysomnographic measures in a community sample. J Clin Sleep Med. 2008;4(6):563-571.

26. Easton SD, Safadi NS, Wang Y, Hasson RG 3rd. The Kessler psychological distress scale: translation and validation of an Arabic version. Health Qual Life Outcomes. 2017;15(1):215. doi:10.1186/ s12955-017-0783-9

27. Translations H. Translated information about health and wellbeing. Australia; 2020. Available from: https://www.healthtranslations.vic. gov.au/bhcv2/bhcht.nsf. Accessed June 24, 2021.

28. Andrews G, Slade T. Interpreting scores on the Kessler Psychological Distress Scale (K10). Aust N Z J Public Health. 2001;25(6):494-497. doi:10.1111/j.1467-842X.2001.tb00310.x

29. Gupta R, Pandi-Perumal SR. COVID-somnia: how the pandemic affects sleep/wake regulation and How to Deal with it? Sleep Vigil. 2020:1-3.

30. Huang B, Niu Y, Zhao W, Bao P, Li D. Reduced sleep in the week prior to diagnosis of COVID-19 is associated with the severity of COVID-19. Nat Sci Sleep. 2020;12:999-1007. doi:10.2147/NSS.S263488

31. Marelli S, Castelnuovo A, Somma A, et al. Impact of COVID-19 lockdown on sleep quality in university students and administration staff. J Neurol. 2021;268(1):8-15. doi:10.1007/s00415-020-10056-6

32. Morin CM, Carrier J. The acute effects of the COVID-19 pandemic on insomnia and psychological symptoms. Sleep Med. 2021;77:346-347. doi:10.1016/j.sleep.2020.06.005

33. Guo Y-F, Liao M-Q, Cai W-L, et al. Physical activity, screen exposure and sleep among students during the pandemic of COVID-19. Sci Rep. 2021;11(1):8529. doi:10.1038/s41598-021-88071-4

34. Korman M, Tkachev V, Reis C, et al. COVID-19-mandated social restrictions unveil the impact of social time pressure on sleep and body clock. Sci Rep. 2020;10(1):22225. doi:10.1038/s41598-020-79299-7

35. R-Foundation. The R Project for Statistical Computing. R-Project; 2020.

36. Team RC. R: A Language and Environment for Statistical Computing Ver. 4.0.3. Austria: R Foundation for Statistical Computing; 2020.

37. Cellini N, Canale N, Mioni G, Costa S. Changes in sleep pattern, sense of time and digital media use during COVID-19 lockdown in Italy. J Sleep Res. 2020;29(4):e13074. doi:10.1111/jsr.13074

38. Zhou Y, Yang Y, Shi T, et al. Prevalence and demographic correlates of poor sleep quality among frontline health professionals in Liaoning Province, China during the COVID-19 Outbreak. Front Psychiatr. 2020;11:520. doi:10.3389/fpsyt.2020.00520

39. Brooks SK, Webster RK, Smith LE, et al. The psychological impact of quarantine and how to reduce it: rapid review of the evidence. Lancet. 2020;395(10227):912-920. doi:10.1016/S0140-6736(20) 30460-8
40. Gan Y, Ma J, Wu J, Chen Y, Zhu H, Hall BJ. Immediate and delayed psychological effects of province-wide lockdown and personal quarantine during the COVID-19 outbreak in China. Psychol Med. 2020;1-12. doi:10.1017/S0033291720003116

41. Tang W, Hu T, Hu B, et al. Prevalence and correlates of PTSD and depressive symptoms one month after the outbreak of the COVID-19 epidemic in a sample of home-quarantined Chinese university students. $J$ Affect Disord. 2020;274:1-7. doi:10.1016/j. jad.2020.05.009

42. Stanton R, To QG, Khalesi S, et al. Depression, anxiety and stress during COVID-19: associations with changes in physical activity, sleep, tobacco and alcohol use in Australian Adults. Int $J$ Environ Res Public Health. 2020;17(11):4065. doi:10.3390/ijerph17114065

43. Gómez-Salgado J, Andrés-Villas M, Domínguez-Salas S, DíazMilanés D, Ruiz-Frutos C. Related health factors of psychological distress during the COVID-19 pandemic in Spain. Int J Environ Res Public Health. 2020;17(11):3947. doi:10.3390/ijerph17113947

44. Ozamiz-Etxebarria N, Dosil-Santamaria M, Picaza-Gorrochategui M, Idoiaga-Mondragon N. Stress, anxiety, and depression levels in the initial stage of the COVID-19 outbreak in a population sample in the northern Spain. Cad Saude Publica. 2020;36(4):e00054020. doi:10.1590/0102-311x00054020

45. Huang Y, Zhao N. Generalized anxiety disorder, depressive symptoms and sleep quality during COVID-19 outbreak in China: a web-based cross-sectional survey. Psychiatry Res. 2020;288:112954. doi:10.1016/j.psychres.2020.112954

46. Gobbi S, Płomecka MB, Ashraf Z, et al. Worsening of Preexisting Psychiatric Conditions During the COVID-19 Pandemic. Front Psychiatr. 2020;11:581426. doi:10.3389/fpsyt.2020.581426

47. Casagrande M, Favieri F, Tambelli R, Forte G. The enemy who sealed the world: effects quarantine due to the COVID-19 on sleep quality, anxiety, and psychological distress in the Italian population. Sleep Med. 2020;75:12-20. doi:10.1016/j.sleep.2020.05.011

48. Xiao H, Zhang Y, Kong D, Li S, Yang N. The effects of social support on sleep quality of medical staff treating patients with Coronavirus Disease 2019 (COVID-19) in January and February 2020 in China. Med Sci Monit. 2020;26:e923549.

49. Leigh-Hunt N, Bagguley D, Bash K, et al. An overview of systematic reviews on the public health consequences of social isolation and loneliness. Public Health. 2017;152:157-171. doi:10.1016/j. puhe.2017.07.035

50. Every-Palmer S, Jenkins M, Gendall P, et al. Psychological distress, anxiety, family violence, suicidality, and wellbeing in New Zealand during the COVID-19 lockdown: a cross-sectional study. PLoS One. 2020;15(11):e0241658. doi:10.1371/journal.pone.0241658

51. Mazza C, Ricci E, Biondi S, et al. Survey of psychological distress among Italian People during the COVID-19 pandemic: immediate psychological responses and associated factors. Int $J$ Environ Res Public Health. 2020;17(9):3165. doi:10.3390/ijerph17093165

52. Cao W, Fang Z, Hou G, et al. The psychological impact of the COVID-19 epidemic on college students in China. Psychiatry Res. 2020;287:112934. doi:10.1016/j.psychres.2020.112934

53. Odriozola-González P, Planchuelo-Gómez Á, Irurtia MJ, de Luis-garcía R. Psychological effects of the COVID-19 outbreak and lockdown among students and workers of a Spanish university. Psychiatry Res. 2020;290:113108. doi:10.1016/j.psychres.2020.113108

54. Sher L. The impact of the COVID-19 pandemic on suicide rates. QJM. 2020;113(10):707-712. doi:10.1093/qjmed/hcaa202

55. Serafini RA, Powell SK, Frere JJ, et al. Psychological distress in the face of a pandemic: an observational study characterizing the impact of COVID-19 on immigrant outpatient mental health. Psychiatry Res. 2021;295:113595. doi:10.1016/j.psychres.2020.113595 


\section{Publish your work in this journal}

Nature and Science of Sleep is an international, peer-reviewed, open access journal covering all aspects of sleep science and sleep medicine, including the neurophysiology and functions of sleep, the genetics of sleep, sleep and society, biological rhythms, dreaming, sleep disorders and therapy, and strategies to optimize healthy sleep.
The manuscript management system is completely online and includes a very quick and fair peer-review system, which is all easy to use. Visit http://www.dovepress.com/testimonials.php to read real quotes from published authors. 